\section{Human Reproduction in Society}

By Derex Llewellyn-Jones. Pp. 547, 115 tables, 69 figures. London: Faber and Faber, 1974. £5.25.

Professor Llewellyn-Jones, whose books on the fundamentals of obstetrics and gynaecology are already widely known and read, has now written this book which deals with human reproduction in the very widest sense.

There are three sections to the book, the first of which discusses the problem of population growth and details the development of demography, the collection of data, natality and mortality. The ecological effects of this growth in world population are outlined and methods of solution to the economic sequelae suggested. In the second section, the technology of birth control is debated together with means of implementation.

The third section discusses social factors in reproductive efficiency and low birth weight infants and both peri-natal and maternal mortality discussed.

The wealth of information in this highly recommended book will be of enormous interest to all personnel concerned in population growth and statistics and all who are interested in the economic and social problems of a rising world population. For medical students, it will provide information on a subject not normally covered in the average medical curriculum and for medical and para-medical personnel involved in this urgent and topical subject, it provides a readable and ready source of information on the widest possible range of subjects in this field.

\section{A History of the Army Medical Department}

By Lieut.-General Sir Neil Cantlie, late DirectorGeneral, Army Medical Services. Two volumes, pp. 967. Edinburgh: Churchill Livingstone, 1974. £12.

This work is the result of more than 10 years' historical research by a former Director-General of the Army Medical Services with the support of the Wellcome Trust. It covers the era from the institution of the Standing Army in 1660 to the formation of the RAMC in 1898 and describes the evolution of the medical services through the long succession of wars which make British history. There are many interesting chapters; the picture of the North American scene in the 18 th century and of the American War of Independence; the origins of the RAMC in which the BMA played such an important part and the evaluation of the role of Sir James Cantlie in developing medical support for the Volunteer and Reserve Army.

It is a scholarly account of the interaction between the Army and its medical services during a period of nearly 250 years. The volumes are impressively produced and well illustrated. The maps and detailed references add to the value of the work. This comprehensive history makes much information available for the first time and will be appreciated by historians and medical officers alike.

\section{The Management of Common Skin Diseases}

By C. P. A. Dupont. Pp. 86. London: Henry Kimpton, 1973. £1.25.

Although even by present-day standards highly priced, this small paperbacked book is well written and likely to be useful to those for whom it has been designed-general practitioners, doctors assisting in skin departments and medical students. It may also be of use to nurses working in skin clinics.

The reader is given a good idea of general principles of local systemic treatment, the skin conditions being arranged basically under alphabetical headings and uncommon ones omitted. Although the space given to details of dressings is small, its content is sound. The index is good and the absence of photographs not important. The remedies are properly given their approved names. It is unfortunate, however, that the metric system is not employed.

One may criticize the text for its suggestion of a barbiturate as a sedative, for its omission of such commonly used measures as electrolysis and wax for hirsutes, and for its advocacy of hexachlorophene sprays; and mention of general anaesthesia for the removal of warts and of prednisone in atopic eczema is perhaps unwise where there can be no elaboration on the very occasional indications for such measures. But it is good to see condemnation of local anaesthetic applications and locally used antihistamines. The general approach is sane and wise and an admirably large amount of useful information is compressed into this well written little book.

\section{Textbook of Medical Treatment}

Edited by S. Alstead and R. H. Girdwood. 13th edition. Pp. 785, illustrated. Edinburgh: Churchill Livingstone 1974. £5.25.

Five editions of this old favourite, first published in 1939 have appeared over the past 10 years, a fact that migh reasonably suggest an up-to-date text. Unfortunately this is not the case. The book retains a dated air, more befitting a much earlier edition. Compare only 35 lines devoted to the drug treatment of gout between attacks, with no fewer than 23 to the dietary aspects. The treatment of GPI and tabes dorsalis each use up more than 3 to 4 times this space. There is no mention of the use of beta blockers or Clonidine in the treatment of hypertension or of high dose IVPs in the management of undiagnosed acute renal failure. There is no space devoted to the treatment of Paget's disease, and certainly no mention of recent advances in this field. Dementia, a major problem in 1974 hospital and non-hospital medical practice receives very scant attention.

The 14th edition would be improved by the pruning of many of the older chapters especially, by a change in balance to emphasize common problems of the 1970 s rather than the 1930 s, and by the provision of an index with heavy type for the major page references. 